\title{
Patricia Aschieri*
}

\section{Corporalidades Ohiversas en M/Sovimiento}

\section{Descentrar la danza de la danza}

Borporeidades Miversas em COnimento

Dança descentrada da dança 


\section{RESUMEN}

Entre el 20 de Mayo y el 7 de junio del año 2020 se realizó el evento "Ciudad Moviente" uno de cuyos propósitos fue el de poner en circulación prácticas inclusivas e igualdad de los derechos de las personas con discapacidad en el campo de la danza. Aunque fuera pensado originalmente para ser desarrollado de manera presencial, debido a la situación de pandemia y aislamiento físico obligatorio dispuesto en Argentina desde el 20 de marzo de este año, los organizadores decidieron convertirlo a la modalidad Online mediante el uso de plataformas y atrayentes estrategias. A partir del trabajo de campo realizado de la línea de los talleres con "participación observante", algunas entrevistas de carácter público y varias comunicaciones personales, se presenta un análisis crítico de las múltiples mediaciones que atravesaron los diversos encuentros y se discuten algunas situaciones sucedidas durante el evento desde el enfoque de la interculturalidad crítica y la teoría de la performatividad.

Palabras clave: danza integradora; inclusión; diversidad corporal; interculturalidad crítica; performatividad

\section{RESUMO}

Entre os dias 20 de maio e 7 de junho de 2020, foi realizado o evento "Cidade em Movimento", que teve como um dos objetivos divulgar práticas inclusivas e igualdade de direitos das pessoas com deficiência na área da dança. Embora originalmente pretendido para ser desenvolvido pessoalmente, devido à atual situação de pandemia e isolamento físico obrigatório na Argentina desde 20 de março deste ano, os organizadores decidiram convertê-lo para o modo online através do uso de plataformas e atrativos. estratégias. Com base no trabalho de campo realizado com "participação observadora" da linha das oficinas, algumas entrevistas públicas e várias comunicações pessoais, é apresentada uma análise crítica das múltiplas mediações que percorreram os vários encontros. Algumas situações ocorridas durante o evento são discutidas sob a ótica da interculturalidade crítica e da teoria da performatividade.

Palavras chave: dança integrativa; inclusão; diversidade corporal; interculturalidade crítica; performatividade 


\section{Corporalidades diversas en movimiento. Descentrar la danza de la} danza

A veces me preguntan y yo digo que no me importa ni la discapacidad ni la pobreza. Me importa el ser humano. Me importa la existencia de todos los seres. Porque si pensamos en discapacidad o en pobreza, no pensamos en lo estructural. Y hay tanta opresión que hace falta pensar en el ser. Mariana Chiliuti* (Encuentro con Sharon Fridman. Minuto 1:09) ${ }^{i}$

\section{Introducción}

Entre el 20 de mayo y el 7 de junio del año 2020 fui invitada a participar de un mega evento denominado "Ciudad Moviente". En este contexto se desarrollaron distintas actividades a partir de tres líneas de programación. El "III Encuentro Latinoamericano de Danza e Inclusión", un ciclo que se viene realizando desde 2013, organizado por la Asociación Civil Argentina Mundo Integrado con Amor (M.I.C.A.) y la Compañía de Danza Sin Fronteras, que convocó a "la corporización de una comunidad internacional de danza e inclusión que celebra la diversidad" ii. Un encuentro con el bailarín y coreógrafo Sharon Fridman. Y un espacio virtual llamado "Moverse en Red", línea que propuso la experimentación a partir de prácticas de taller, a cargo de diferentes compañías de danzaiii. La invitación explicitó el interés de poner en circulación prácticas inclusivas e igualdad de los derechos de las personas con discapacidad en el campo de la danza.

Aunque fuera pensado originalmente para ser desarrollado de manera presencial, debido a la situación de pandemia y aislamiento físico obligatorio dispuesto en Argentina desde el 20 de marzo de este año, los organizadores decidieron convertirlo a la modalidad on line mediante el uso de plataformas y atrayentes estrategias. Como performer y antropóloga, y en mi condición 
de artista-investigadora, me propuse realizar una "participación observante" (WACQUANT, 2006; ASCHIERI, 2013; entre otros), de la línea de los talleres. Sitúo mi perspectiva como espacio epistemológico específico de producción de conocimientos que pone especial atención a la experiencia/vivencia. Ello es así, pues considero que los/as artistas investigadores/as iv tenemos habilidades y potencialidades sensoriales, perceptivas, kinésicas, etc. que se ponen en juego de modo particular en nuestras actividades investigativas a partir de nuestras específicas trayectorias corporales ${ }^{\vee}$. Sin embargo, en la medida en que nuestros "habitus" (BOURDIEU, 1980) de investigación en la academia, tienden a que no prestemos atención a estos momentos experienciales, propongo considerarlos y constituirlos como parte de una metodología legítima para conocer/saber. En mi caso, utilizo lo que denomino la metodología de la "sensocorporreflexión" (ASCHIERI, 2017, 2018), que involucra incorporar, utilizar y crear técnicas específicas, que favorezcan la apreciación de las dinámicas entre cuerpo y representación, entre imagen y movimiento y/o entre gestos, pensamientos y escenas. Mi enfoque plantea considerar como espacio de producción de conocimiento, la dirección que va desde la experiencia a la conceptualización (del movimiento a las ideas). Es decir, propongo que los/as artistas investigadores/as den lugar a una sensibilidad perceptiva que colabore en la identificación de aquellos momentos esceno-teóricos en que experimentamos instancias con alto potencial de teorización, en la medida en que el recorrido que va de los conceptos a la dramatización-movimiento-obra, estaría mucho más legitimada.

A continuación, y teniendo en cuenta mi propia trayectoria corporalvi, mis apuntes de campo y algunas entrevistas de carácter público, presentaré las reflexiones que suscitó mi participación en este evento, a partir de realizar 
un análisis crítico de las múltiples mediaciones que atravesaron los diversos encuentros que estuvieron signados por la modalidad on line. Posteriormente discutiré algunas situaciones sucedidas durante el evento desde el enfoque de la interculturalidad crítica y la teoría de la performatividad.

\section{La política de las palabras. Mediaciones I. De la discapacidad a la} diversidad. ¿Integrar, incluir?

La línea de talleres de "Ciudad Moviente" abarcó una programación variada que cruzó transversalmente los eventos "Moverse en Red" y el "III Festival Latinoamericano de Danza e Inclusión". En ellos se propusieron distintos temas de debate, como por ejemplo, los derechos de los y las trabajadores/as de la danza o los recursos de los que disponen los/las creadores/as. También se impartieron clases de variadas prácticas y metodologías de movimiento, como bioenergética, juegos teatrales, el enfoque de la tensegridad, la danceability, entre otras ${ }^{\text {vii }}$.

Las palabras sitúan, categorizan y clasifican jerarquizando al nombrar e invisibilizando al omitir. Al respecto Pierre Bourdieu (2007) sostiene que las palabras son poderosos instrumentos a partir de los que pueden hacerse existir públicamente, cosas/grupos que no existían sino en estado implícito o confuso, incluso hasta reprobado. Este hecho de producir categorizaciones, o incluso de rechazarlas, no es un asunto menor. El poder de nombrar es un poder inmenso que suele ser ejercido por quienes se sienten legitimados.

Precisamente, la palabra discapacidad es una de las categorías que viene siendo, desde hace algunos años, puesta en cuestión. Un campo de disputas que interpela "sentidos peyorativos que se encuentran tan sedimentados que la lucha por el significado debe implicar al propio 
significante" (GRIMSON, 2010, p.12). En este sentido, el nombre del Festival es parte de estas dinámicas. Como antecedentes de este "III Festival Latinoamericano de Danza e Inclusión" pueden citarse el "Encuentro Rioplatense de Danza Integradora" (Año 2013) y el "Encuentro de danza e Integración Latinoamericana" (Año 2015). Ambos antecedentes mencionaron la categoría de "danza integradora", para aludir a que se trataba de un encuentro de danza que podía ser practicada por personas con y sin discapacidades, mientras que el actual referencia la danza en relación a la "inclusión".

A lo largo de los años, la discapacidad fue nombrada con variantes de vocablos que destacan desde la falta, hasta con aquellos que enfatizan en su condición de personas. Muchas de estas propuestas buscan trascender la connotación negativa de la palabra discapacidad y han planteado, acorde a la Convención Internacional de Derechos de las Personas con Discapacidad (2006) viii, un cambio desde el "modelo rehabilitador" hacia el "modelo social". Resulta relevante mencionar que desde el propio campo de las personas con discapacidad, fueron propuestas categorías como "diversidad funcional"ix o personas con "funcionalidad diversa" (ROMAÑACH y LOBATO, 2005; ROMAÑACH y PALACIOS, 2008). Estos términos no constituyen conceptos médicos, sino que buscan nombrar a aquellas personas que funcionan de modos diversos. La "diversidad funcional" incluye a personas con diversidad funcional física, intelectual, sensorial, emocional, orgánica, y salud mental, entre otras. El objetivo no es desconocer las diferencias desde el punto de vista biofísico, sino reconocerlas. Al mismo tiempo plantea un enfoque que pone a la diversidad en perspectiva con aquellas situaciones que las estructuras normalizantes imponen para resolver las circunstancias de la vida. Incluso la normalización llega en algunos casos, aunque sin necesitarlo 
realmente, a obligarlos/as a solucionar ciertas situaciones mediante la recurrencia a otras personas.

No obstante, estos términos "nativos" aún no han tenido una amplia difusión y son pocas las personas que suelen auto-identificarse desde la categoría de "funcionalidades diversas" y persiste la utilización de la palabra discapacidad como forma de auto-nominación ${ }^{x}$.

En Argentina hace ya 30 años comenzó a hablarse de Danza Integradora para referir a la danza en la que participan personas con esta condición. Fue la profesora Susana González Gonz, quien en 1991 la impulsó como campo específico a partir de el proyecto "Todos Podemos Bailar" modalidad de la danza, se constituyó desde entonces como un espacio de investigación sobre la inclusión y la integración de bailarines/as con y sin discapacidad a partir de la que González Gonz creó una metodología que integra diversas técnicas entre las que se mencionan especialmente, las de Danza Contemporánea, Conciencia Corporal y Autoconocimiento y Expresión Corporal. Este espacio fue el semillero del que, en el año 1996, surgió el grupo Alma que desde entonces ofrece distintos programas de espectáculos. Como un desprendimiento de este grupo inicial, en 2014 surge Danza sin Fronteras. En una entrevista y acorde a las palabras citadas en el epígrafe, Mariana Chiliutti - quien fuera una de las organizadoras del evento y actual directora de esta compañía - refiere sobre el cambio, uso y desuso de estos vocablos que para ella "son todas palabras que sobran" ya que "la diversidad es inherente al ser humano".

Cuando pensamos en-desde el amor, uno, creo que no incluye, no integra, no hace más que el esfuerzo de compartir y estar y ver que se construye entre los que somos parte. Integración me parece que da la posibilidad de ser actores activos, de que suceda la inclusión. Inclusión es una palabra que corresponde usarla por estamentos que surgen de Naciones 


\begin{abstract}
Unidas por los derechos de las personas con discapacidad. Entonces bueno, lo correcto es usar la palabra inclusión. Yo insisto, si hablo de amor, no hablo de inclusión. Compartimos juntos (...) ¿Por qué hay que dar un nombre cuando hay una persona que tiene un nombre y un apellido? ¿y qué responsabilidad tengo yo tanto social, como ciudadana, como política, de poder prever qué necesita el otro? Y entonces, ahí soy responsable.(Chiliutti. Entrevista Pública) ${ }^{\mathrm{xii}}$
\end{abstract}

Como puede apreciarse, anteponer la persona sobre la condición diversa, nos lleva a pensar en términos de sujetos de derechos, lo cual implica ponderar el rol de ciudadanos/as y de sujetos/as responsables con capacidad de agencia. La variación en la nominación supone el pasaje del modelo rehabilitador (desde el que el vocablo "integración" queda asociado a la posibilidad de acceder a un "todo" específico, ya sea educativo, laboral, etc. y que involucraría el refuerzo de la diferencia), al modelo social que ubica la inclusión como el acceso a un todo más amplio en clave de igualdad de oportunidades. No obstante, algunos/as artistas continúan utilizando el término "integrar" en la medida en que tienen una concepción no sectorizada, sino amplia y abarcadora de la totalidad en la que se practicaría la integración. Como señala el coreógrafo inglés Adam Benjamín se trata de lograr "algo que está conectado y en la que todas las partes componentes contribuyen al todo" (en BRUGAROLAS ALARCÓN, 2015). Alma, el primer grupo en Argentina, continúa utilizando la nominación "danza integradora" para definir su particularidad.

Quisiera considerar a continuación, una breve historización de la corriente de pensamiento que impuso el uso de la palabra "inclusión" vinculado al reconocimiento de derechos de las minorías. El "Sistema de protección integral de los discapacitados"xiii, es parte de un proceso que luego adquiere mayor protagonismo en la década de los 9o' en el que, al mismo 
tiempo que se expandía el capitalismo a partir de la profundización de las políticas neoliberales, América Latina se reconoció como un espacio multiétnico y plurilingüistico poniendo énfasis en las diversidades. Década histórica en la que muchas luchas encontraron eco en la consagración de los derechos de sectores de la población hasta ese momento desplazados/invisibilizados/excluidos.

Cabe señalar que el proyecto neoliberal produjo una transformación de las relaciones entre el Estado y la sociedad, que involucró la difusión e implementación de políticas multiculturalistas que trajeron reformas jurídicas, educativas, constitucionales, etc. Se trató de un proceso de "recolonización" que, poniendo el eje en el reconocimiento político de nuevos/as ciudadanos/as, impuso la razón neoliberal sobre cosmogonías basadas en otras epistemologías. Las ideologías multiculturalitas que acompañaron estos procesos, pusieron en marcha estrategias esencializadoras de la diferencia, situando, clasificando y ordenando a partir de los valores de la tolerancia e impulsando lo que se denominaron "políticas de inclusión". Investigadoras como Catherine Walsh (2008) advierten que no se ha prestado suficiente atención a estos procesos, que fueron diezmando y/o subalternando con mayor profundidad estos "otros modos de ser y de hacer" y que tuvo y tiene como brazos ejecutores, a las instituciones internacionales financieras de proyectos socioculturales, así como a los organismos gubernamentales y de la sociedad civil, tales como las ONG. Estas instituciones ofrecen apoyos a cambio de que quienes los reciben, acepten poner en juego micro prácticas, cuyas lógicas responden la razón económica neoliberal que desconoce, imperceptiblemente pero con tenaz eficacia, a sus propias dinámicas y modos de ser y de hacer. Es interesante tener presente que "inclusión" es un término que siempre supone su opuesto, 
es decir, "exclusión". El binomio inclusión/exclusión pone en juego, sin mencionarlas, las relaciones de poder que, en este caso, indicarían que existen personas con y sin discapacidad en desigualdad de condiciones

Precisamente, el III Festival cuenta con un subsidio de Mecenazgo y la decisión de cambiar la palabra "integrar" por la de "inclusión" está signada por estas dinámicas. En las palabras de uno de los integrantes de la organización que comparto a continuación, puede apreciarse la imposición de sentidos, distintos a los del colectivo, cuando reconstruye una discusión entre compañeros/as y justifica este cambio por ser "políticamente correcto".

Porque es la forma que se encontró con el convenio de las personas con discapacidad, por el mismo hecho que no son personas con discapacidad y no son discapacitados o discapacitantes. Es $X$ que tiene una discapacidad. Una persona, un sujeto de derecho que tiene una discapacidad que no está integrada (remarca esta palabra) sino está incluida (remarca esta palabra). Por eso el concepto de inclusión y no de integración. Porque es muy claro en unos dibujitos, creo que hay algo muy pedagógico, que cuando vos hablas de integración, hablas de un sector. Por ejemplo, de personas con discapacidad que están juntas en un ámbito más grande y cuando hablas de inclusión hablas de personas con discapacidad que están repartidas en un círculo más grande que es la sociedad. Por eso se hace tanto hincapié en esa distinción. La distinción que después conlleva lo que pensás o querés de que somos todo diversos o somos todos diferentes, todos tendríamos que estar incluidos. Está bien es válida. Pero no es lo que se usa. No es la forma políticamente de expresarlo. Lamentablemente hay que hacerlo así. Hay que hacer una distinción con eso. (Mariano. Integrante de la Compañía Danza Sin Fronteras)

Así, "inclusión" forma parte de una dinámica en la que la diferencia es percibida como bien cultural ponderado positivamente y que constituye un valor en el marco del mercado de acceso a las políticas culturales. Ser "disca" o trabajar para los "disca"xiv y realizar acciones para fomentar la "inclusión", 
puede ser clave a la hora de acceder con mayor facilidad a los subsidios o fondos que otorgan ciertos organismos, incluyendo los del Estado. $Y$ en este juego de palabras/beneficio, queda obturada la visibilización de los procesos de producción y reproducción de las diferencias, que a la vez son producción y reproducción de las desigualdades

\section{La política de las palabras. Mediaciones II. El desafío de construir un campo del arte desde la perspectiva de la diversidad.}

En Argentina como parte de las artes escénicas, la danza siempre debe luchar por acceder a las políticas culturales. Esta tendencia también se pone en evidencia a la hora de reconocer "el derecho de los/as hacedores de la danza como trabajadores/as"xv . En pos de sostener acciones para la pronta sanción de una Ley Nacional de Danza, una de las actividades organizadas en la programación de "Moverse en Red" fue una charla sobre los derechos laborales. Como se sostuvo en la convocatoria, "la danza es un sector dentro de las industrias culturales que tiene dificultad para vincular su hacer en el marco de una actividad laboral". En esta dirección, se conversó largamente acerca de la dificultad que acarrea la consideración difusa respecto de los límites entre arte y vida y los convenientes equívocos que esta visión conlleva. Es decir, los/as artistas pueden reconocerse como tales pero dado "que gozan" de su hacer y lo hacen como parte de su "identidad irrenunciable", sus acciones no serían trabajo. Esta valoración simbólica de la actividad, media su auto-percepción identitaria lo cual dificulta que se vean a sí mismos/as como trabajadores/as y que, convenientemente, tampoco sean reconocidos/as por el Estado como parte un colectivo con derechos laborales. Al respecto, en una comunicación personal, Mariela Ruggeri quien estuvo a cargo de la charla en el evento, refirió la relatividad de las hegemonías y de 
las relaciones de poder en el campo dancístico, en la medida en que dependen de "auto-percepciones sesgadas" relacionadas con una "la falta de conciencia cívica en cuanto a construcción de derechos y a la organización para conseguirlos" ${ }^{\prime \prime v i}$. En su opinión resulta muy difícil percibirse como sector en la medida en que "la particularidad del objeto danza" "recrea universos unipersonales y comunidades cerradas determinadas por sus propias estéticas" ${ }^{\prime \prime v i i}$.

Esta situación podría explicar en algún grado, que en este encuentro no se mencionaran las particulares condiciones de los/as trabajadores/as de la danza con funcionalidades diversas. De lo conversado en esa oportunidad, y a la luz de la trayectoria del Movimiento Federal de Danza y otros colectivos, puede comprenderse que aún es tal la magnitud de aquello que falta organizar y conseguir en el campo de la legislación, que tal vez no sería el momento oportuno para detenerse en situaciones específicas. $Y$ esto seguramente es así. En Argentina aún no tenemos una ley de danza y desde el año 2008 viene accionándose incesantemente en pos de lograr su

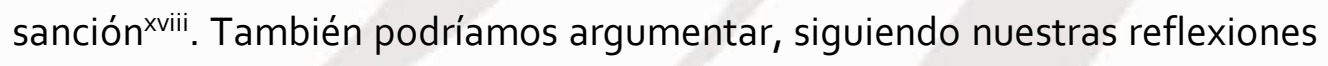
de apartados anteriores, que pensar en términos de diversidad funcional, es decir en clave de los derechos específicos de un sector del campo de la danza, supondría continuar la línea de normalización que subraya la diferencia. Entonces, al hablar de los derechos de los/as trabajadores/as de la danza, no habría razón para poner en evidencia las diversidades.

Sin embargo, al tratarse de un evento que se realizó en el marco una convocatoria con énfasis en la participación de una población que viene luchando, como sostiene Chiliutti, desde "los márgenes" del campo dancístico por la integración y la inclusión, creo oportuno hacer el esfuerzo y reflexionar más allá de estos razonables posibles motivos. Mi intención no es 
juzgar este tipo de omisiones, sino simplemente pensar acerca de sus implicancias y en todo caso, contribuir en la construcción de un campo de la danza que pueda descentrarse de sus propias hegemonías y de las relaciones de poder que la atraviesan.

Un breve recorrido de los vínculos entre arte y discapacidad permite apreciar que históricamente su articulación ha tendido a vincular la danza a los discursos terapéuticos y educativos, en los que lo expresivo cumpliría una función alejada del hecho artístico en sí mismo. Por supuesto que hay excepciones que trascienden las adversidades y los prejuicios sociales, y hubo y hay artistas con alguna condición asociada a la discapacidad que logran algo de reconocimiento. Sin embargo, suele destacarse desde discursos "capacitistas" su condición de personas heroicas en tanto han logrado, a partir de su tenacidad y deseo, desafiar los obstáculos que la naturaleza o la fatalidad les impuso. Como ejemplo cercano, citamos el caso de la bailarina Gabriela Torres del Grupo Danza Sin Fronteras, que en una nota periodística fue caracterizada como la Mujer Maravillaxix. Al respecto Ruggeri en la misma comunicación comenta:

Creo que esto se relaciona con la pobreza del campo en toda su magnitud. La danza en Argentina no tiene un desarrollo que permita análisis conceptuales que puedan evaluarla en tanto arte. Se hace con escasos recursos en algunos casos puntuales y más ligados a estéticas "académicas" o contemporáneas. Si observamos DV8, al bailarín sin piernas nunca se lo juzgaría como "hombre maravilla". (Comunicación personal. Octubre 2020)

Es decir, nuestros "habitus" no nos permiten asociar una condición de discapacidad con la danza y el hecho artístico. No obstante, aunque sin tener 
difusión y trabajar intensamente desde los anonimatos, es justo destacar que en Argentina son varias las compañías de danza integrada/inclusiva/mixta que llevan adelante sus producciones. Es el caso de los mencionados Alma y Danza Sin Fronteras, así como Sin Límites, Andares, Pulsiones -que participaron en este Festival- y otros como Delamano (Neuquen), Cielo Alpa (Ticara, Jujuy) Agrupación Cre-arte (Bariloche- Rio Negro) y Emergente, entre otros.

En uno de los talleres posteriores al citado, se mencionó las particulares dificultades de acceso, traslado y espacio que tienen algunos/as bailarines/as. Entre ellas, se hizo referencia a la necesidad de contar con vehículos para llevar sillas de rueda u otros dispositivos, la dedicación de gran cantidad de tiempo a distintas actividades, incluyendo aquel que supone el viajar hasta los lugares de ensayo o funciones, así como también se señaló la frecuente necesidad de contar con asistentes específicos, en tanto sus condiciones especiales de movilidad y desempeño. Más allá de que no hubiera habido un temario previo en el que se hubiera acordado tratar las necesidades de un sector de la danza en particular, cabe una reflexión acerca de por qué en una reunión sobre los derechos de trabajo, nadie hizo alusión a estas condiciones de producción específicas, si como puede apreciarse, resultan cruciales a la hora de pensar un campo dancístico integrado en igualdad. Resulta entonces preciso volver sobre la condición lábil del campo dancístico en Argentina, independientemente del tipo de danza del que se trate. Como señala Ruggeri los/as hacedores/as de la danza se desempeñan en importantes condiciones de precariedad:

La danza no oficial, que es el 95\% de la danza del país vive de dar clases. Los estertores artísticos (obras) son hechos que sobreviven por pulsión de juventud o exceso de energía y 
siempre bajo condiciones absolutamente precarias donde nadie gana nada. Los discursos exitistas de acuerdo a mi experiencia se relacionan con lógicas de supervivencia que no dejan de ser perversas porque naturalizan lo precario y son funcionales a quienes precarizan. En la medida en que no se siga trabajando para cambiar las condiciones seguiremos peleando lugares ficticios. (Comunicación personal. Octubre 2020)

Resulta evidente que los discursos exitistas e individualistas, o incluso la invisibilización involuntaria de las variantes condiciones de producción de los/las bailarines/as, son el resultado de un enmascaramiento sistemático de las luchas cotidianas, de las micropolíticas que de manera individual y colectiva se llevan a cabo silenciosamente. En este sentido se hace necesario dar lugar a un profundo debate y proceso reflexivo que nos lleve a comprender las tensiones que subyacen a estos procesos de omisión/invisibilización/des-conocimiento/subvaloración, Hablar de danza integrada o de danza inclusiva o pensar en procesos de inclusión/integración de ciudadanos/as con derechos, necesita actualizar una discusión crítica acerca de las lógicas que el poder propone que, como sostiene FOUCAULT (1987), es estratégico, infinitesimal y deslocalizado.

La exigibilidad de derechos debe considerar "modos de sery de hacer" propios que supongan igualdad en la diversidad y no tolerancia en la diferenciación. Resulta urgente potenciar el proyecto político, social, epistémico y ético que propone la diversidad, a partir de la explicitación de las condiciones de los diálogos, o en todo caso, las causas de sus ausencias.

\section{La política de los movimientos y de las palabras Online. Mediaciones III.}

\section{Cuerpxs Multi D.}

Patricia Aschieri - Corporalidades diversas en movimiento. Descentrar la danza de la danza. 
Como ya he comentado la situación particular de encontrarnos vía plataforma virtual, constituyó un verdadero espacio inédito de exploración que desafió la imaginación de profesores/as y talleristas. Confieso que al recibir la invitación para participar, experimenté una gran curiosidad y cierta ansiedad en saber cómo se llevaría a cabo una experiencia que usualmente está centrada en el "convivio" (DUBATTI, 2002). Cómo se reemplazaría o transformaría lo presencial para articular un tiempo-espacio con coordenada virtual, en encuentros telemáticos donde el intercambio sólo puede estar medido por las pantallas.

Al asistir a los primeros encuentros y como asidua artistainvestigadora-practicante de-en-desde-con talleres, me sentí interpelada por el hecho de tratar de comprender en qué consistía aquello que yo había dado por sentado en los encuentros presenciales. Qué sería aquello que la virtualidad venía a poner en crisis y que parecía ser trascendido por el entusiasmo y la creatividad de todos los/as participantes. Arriesgo algunos pensamientos sueltos escritos en mi cuaderno:

Lo privado trastocado en espacio público, La posibilidad siempre disponible de convertirnos en una especie de cuadradoavatar, que igual puede dar cuenta de nuestra presencia.

La visión enmarcada en la bidimensionalidad que diluye el volumen de los cuerpos,

La falta de con-tacto,

La im-percepción de la energía,

Una nueva administración /distribución de lo sonoro y la palabra en la que podemos estar "muteados/as" y en la que hay una imposible convivencia/superposición de voces/sonido

Quedar congelados/as, involuntariamente ausentes.¿Estar solos/as? (Notas de Campo. Mayo 2020)

Durante los sucesivos encuentros, organizados en pequeñas ventanitas que asomaban desde nuestras pantallas, alguien dijo que parecíamos "vecinos/as" de un gran edificio. Y así, sin pensarlo, se volvió habitual hacer referencias a nuestra presencia co-participante de ese modo. 
Una confluencia de personas de distintas partes de Argentina (desde la Patagonia hasta Misiones), Brasil, Venezuela, México, España, Alemania, entre otras.

Entonces, pese a todos los obstáculos, el espacio virtual de la plataforma posibilitó el encuentro de personas geográficamente lejanas. Desde la cuadrícula on line alineada en filas (alguien dijo que parecíamos las ventanas de un edificio) se escuchaba -"Hola, te vi el otro día en el taller, pero no pude saludarte. ¡Qué emoción volverte a encontrar! - Una suerte de "vecinos/as" que, es importante decir, en las "normales" circunstancias de presencialidad tal vez, no hubieran podido conocerse, encontrarse, bailar y crear juntos/as.

La pantalla se constituyó en una especie de tela que alojó la creación de una verdadera red de movimientos, acciones, voluntades, deseos, preguntas. Una gran coreografía involuntaria, y al mismo tiempo consciente desde el deseo puesto en movimiento por las consignas de los "profesores/as", "facilitadores/as" y "maestros/as", que nos invitaban a acercarnos, a conectarnos con ciertas partes de nuestros cuerpos, con las gestualidades de otros, o a proyectar específicas formas de danzar.

Las condiciones perceptuales se habían modificado dramáticamente y transformaron nuestros "modos somáticos de atención" (CSORDAS, 1993). Me refiero a nuestros modos de atender a nuestras corporalidades y las corporalidades de los otros, donde ya no pudimos articular del mismo modo las conjeturas que alimentan nuestra imaginación sensorial, basadas en el olor y la cercanía de otros cuerpos, en las sensaciones y circulación de vibraciones compartidas. Allí estábamos, respondiendo desde un deseo que no se reconocía en la proximidad de los cuerpos sino en la co-participación 
temporal mediada por la pantalla. ¿Cuál era, me pregunté entonces, el riesgo ontológico que nos proponía la bidimensionalidad virtual?

Describiré a continuación una particular circunstancia que ocurrió en uno de los talleres y que, desde mi punto de vista, enriqueció el diseño de las consignas de acuerdo a un espacio sensible que alojara la amplitud que propone la diversidad.

En el marco de lo que yo entendía como uno de los talleres con mayor escucha y decir sensibles a las dificultades propias de nuestras distintas condiciones corporales y de existencia material (situación de aislamiento, espacio de movimiento, condiciones sonoras, etc.), una participante refirió que no se sentía incluida ya que las consignas no tenían en cuenta su condición de disminución visual. Más allá de las vicisitudes que rodearon a este hecho, en términos de las acciones que inició la organización y sobre las que no viene al caso detenerme en este momento, quiero remarcar que su reclamo tuvo interesantes consecuencias en los talleres subsiguientes. Fue a partir de ese momento que comenzó la utilización de un recurso muy utilizado en las poblaciones con disminución visual: la audio-descripción. A través de nuestros dispositivos comenzaron a escucharse palabras que narraban las acciones de las personas que conformaban esta circunstancial comunidad de vecinos/as: "una chica de remera roja y pelo largo balancea su pierna de modo circular hasta dejarla reposar en el suelo". Esta estrategia logró traer, y atraer desde otros lugares y geografías, la presencia de los vecinos/as co-participantes en movimiento.

Así, desde una de las "ventanitas" encontraba cuerpo la palabra, acercándonos otros cuerpos "y otras cuerpas", en tiempo y espacio, tocándonos, con-tactándonos. El sonido y significados de las frases sonorizadas y ritmadas, nos modificaban y nos transformaban, nos 
acariciaban corporizando-se, corporizando-nos desde nuestras propios movimientos tocados por otro devenir cinético. Los solitarios cuerpos -con y sin disminución visual-. mutamos a cajas de resonancia, y la piel, nuestra piel, fue la tela en la que reverberaron las palabras-movimiento propias y ajenas, personales y compartidas, extrañas y cercanas. Inesperadamente, recuperamos el volumen.

Entiendo que este recurso en las condiciones del digito-convivio, amplificó la posibilidad de producir resonancias en las corporalidades, dando lugar a otra calidad de la presencia. Mi hipótesis sostiene que nos vimos compelidos/as a reinventar el propio cuerpo apelando a nuestra imaginación de modo inéditamente discursivo. Este tipo de agenciamiento operado como estrategia por parte de los/as profesores/as y maestros/as a cargo de los talleres, jugó un tipo de rol similar al de esa energía invisible pero percibida en la condición de co-presencia. En este sentido, logró reponerse el espacio vibrante que se genera entre cuerpos. Es decir, en nuestra condición de vecinos/as de pantalla, fuimos sin ser conscientes de ello, partícipes activos de la construcción de una imprescindible y necesaria nueva proxémica de los cuerpos y del deseo. Aventuro que este tipo de imaginación sensorial, suscitada por estas otras formas inusuales de la presencia telemática propició la magnífica oportunidad para una potencial subversión y expansión de nuestras corporalidades que pudieron sortear, al fin, esa insistente tracción a la bidimensionalidad

\section{Palabras finales. Cuerpar como acción transformadora}

La teoría de la performatividad sostiene que en tanto sujetos sociales, nos atraviesan activas y eficaces matrices que se constituyen a partir de 
nuestra potencialidad para "citar" normas hegemónicas. La performatividad supone que esas matrices son citadas "y reiteradas, logrando su efecto mediante su naturalización en el contexto de un cuerpo" (BUTLER, 1999, p.15). Aquellas que no corresponden a las hegemónicas, definidas por nuestros posicionamientos identitarios, se confinan al campo de "lo abyecto". Pero hay también un espacio indeterminado en el que no estaríamos condenados a reproducir solo lo legitimado y hegemónico. En cada acción en que "la cita" se produce, es posible resistir opresiones y/o accionar "deslizamientos para dar lugar a otras opciones" (BUTLER, 2002).

Un ejemplo actual, activo y dinámico de estos espacios de disputa es el del lenguaje inclusivo, que es importante mencionar, ha sido una práctica habitual de quienes participaron en los talleres propuestos por el evento Ciudad Moviente. Este tipo de deslizamientos también tuvo lugar cuando se dio espacio a una semiopraxis corporal propia de un campo excluido, como la audio-descripción. Como he descripto, este agenciamiento tuvo repercusiones inusitadas en las corporalidades y subjetividades de quienes participamos de la experiencia expandiendo las corporalidades en su tridimensionalidad y percepción. Un saber hacer desde los márgenes, con consecuencias aún insuficientemente exploradas.

Para finalizar. quisiera describir otra poderosa subversión que se propició cuando alguien instó a los teleparticipantes a que "cuerpemos". Precisamente, solo unos días antes, yo había escrito un artículo en el que sostenía la necesidad de inventar verbos y nuevas formas de nombrar ${ }^{\mathrm{xx}}$. Según mi opinión, la circunstancia sorpresiva de la pandemia, había puesto en evidencia la incapacidad de ciertas categorías incuestionadas. Me preguntaba cómo era posible expresar lo que nos estaba/está pasando, si ya no sirven las viejas categorías para analizar y comprender esta inédita 
situación que nos encierra físicamente, y que nos vuelve desconfiados/as de la proximidad de los otros cuerpos. En el artículo aludido, me referí específicamente a la posibilidad de transformar el sustantivo cuerpo en verbo. Cuerpar, expresaría la experiencia de ejercer todo el derecho de las corporalidades a transformarse y tratar de comprenderse en estas nuevas condiciones de distanciamientos y bidimensionalización virtual.

Cuerpar devuelve a las corporalidades la referencia a la acción. Al considerar brevemente la palabra danza podemos apreciar que no es solo un sustantivo, sino que es susceptible de convertirse en verbo. Sin embargo, cuerpo o corporalidad en su condición sustantiva, suelen ser vocablos que resultan insuficientes para decir/describir/narrar/analizar lo que los cuerpos y "las cuerpas" hacen. Quienes trabajamos en el campo de lo corporal desde distintas disciplinas, hace mucho tiempo lo sabemos, no obstante lo dejamos en el plano de lo anecdótico o en el espacio de lo intuido. Estos momentos que yo llamo "sensocorporreflexivos", son objeto de invisibilizaciones y, hasta el momento, no los hemos evidenciado suficientemente. Sujetos/as al lenguaje, venimos reproduciendo las relaciones de poder en las que fuimos socializados/as y renunciamos a esa capacidad reflexiva y de agencia que se abre en el campo de indeterminación -políticamente encubierto- producto de la tensión entre el "habitus" bourdiano -y su tendencia a la reproducción- y la "performatividad" butleriana y su potencialidad para la acción.

Cuerpar en la red, condensa un acto de insurrección que hace caso omiso de los poderes que oprimen nuestra capacidad creativa y que insiste en obligarnos a reiterarnos en los límites de lo enunciable. Cuerpar condensa una micropolitica "desde abajo" que acciona creando líneas de fuga hacia otras potencialidades. Los/as académicos/as solemos ser creativos a la hora de adjetivar haciendo confluir adjetivos y sustantivos, o viceversa, pero casi 
nunca proponemos nuevos verbos ${ }^{x \times i}$. Tal vez sea porque es el nudo de la acción, el exacto lugar del drama. Como artista investigadora entiendo que los/as artistas y sus prácticas, proponen lógicas cognoscentes que pueden sugerir impredecibles direcciones y poderosas mutaciones ${ }^{\mathrm{xxii}}$.

¿Qué pasaría si nos descentráramos de las tendencias que nos imponen, si dejáramos de "citar" las normas volviéndonos agramaticales, ya no solo desde nuestra diversidad corporal, siempre manifiesta pero invisibilizada y oprimida, sino desde una práctica descentrada siempre abierta a otras epistemologías? "Nosotros sí que sabemos de dificultades", fue la frase que sostuvieron los/as organizadores/as en la convocatoria del evento al referirse al desafío de convertir lo que iba a desarrollarse de modo presencial, al formato virtual. Estas "dificultades" son un espacio de obstáculos claro está, pero también es un ámbito de poderosos saberes y activas epistemologías.

La danza integrada/inclusiva constituye un espacio genuino y especifico en el que se experimentan "otros modos de ser y de hacer", que producen rupturas tendientes a la humanización proponiendo micropolíticas de subversión y creación. La deshumanización/colonización ha sido, justamente, el resultado de un orden injusto que propicia, como condición necesaria, la violencia de los opresores en todas las formas posibles explícitas e implícitas. Se trata entonces de descolonizar/humanizar a partir de fomentar "una praxis critica", en tanto proceso continuo de reflexión-acciónreflexión (WALSH, 2008). Identificar las raíces de las estructuras opresoras para poder actuar sobre ellas y posibilitar ámbitos de subjetivación abiertos hacia nuevas significaciones, hacia la pluridimensionalidad dinámica de haceres que quiebren la maquinaria de la reproducción. 
Mi intención ha sido dar cuenta de esos espacios de enunciación en los que pueden vislumbrarse los hilos del poder, al dar lugar a las voces invisibilizadas, a los silencios involuntarios, a las tensiones y las luchas que vienen sosteniéndose desde la danza como campo "que está en los márgenes", así como aquellas que se dan en sus propios "márgenes". Intento contribuir a un proceso de deconstrucción en un sentido plural e igualitario, que abrace las infinitas posibilidades de la diversidad de las corporalidades en movimiento, como fuente de emancipaciones, de conocimientos y de creaciones. En este sentido, he querido poner en evidencia las vías que "desde abajo" vienen gestándose para construir "tecnologías del amor" (Chela SANDOVAL en Walsh 2008), o también podríamos llamarlas tecnologías de humanización, de reconocimiento mutuo y de empatía, para continuar descolonizando nuestra imaginación.

\section{REFERÊNCIAS}

ASCHIERI Patricia. Subjetividades en movimiento: Reelaboraciones de la danza butoh en Argentina. Buenos Aires, Editorial de la Facultad de Filosofía y Letras. Universidad de Buenos Aires. 2019.

Del movimiento a las ideas. Reflexiones en torno al status epistemológico de la corporalidad en los estudios pertenecientes al campo de la antropología de la danza. Conference Proceedings Anais.18th IUAES World Congress International Union of Anthropological and Ethnological Sciences. Comp. Miriam Grossi y otros. pp. 4969 4980. 2018

---------- Experiencias liminales en investigación. Devenires de una anfibia entre el arte y la academia. En Múltiples Olhares sobre procesos descoloniais nas Artes Cénicas Orgs. Mundim, Braga, Veloso. Telles. Paco Editorial pp. 73-92. 2017

Hacia una etnografía encarnada: La corporalidad del etnógrafo/a como dato en la investigación" En X Reunión de Antropología del 
MERCOSUR: Situar, actuar, imaginar antropologías desde el Cono Sur. Argentina, Universidad Nacional de Córdoba. 2013

BOURDIEU, Pierre. El sentido práctico. Buenos Aires, Siglo XXI. 1980.

Cosas Dichas, Buenos Aires: Gedisa Editorial. 2007

BRUGAROLAS ALARCÓN Maria Luisa El cuerpo plural. Danza integrada en la inclusión una renovación de la mirada" Tesis Doctoral Programa de Doctorado en Arte: Artes Visuales e Intermedia Departamento de Escultura Facultat de Belles Arts Sant Carles Universitat Politècnica de València. 2015

BUTLER, Judith. El género en disputa: El feminismo y la subversión de la identidad. Buenos Aires: Paidos. 1999

Cuerpos que importan: sobre los límites materiales y discursivos del sexo. Buenos Aires: Paidos. 2002

CSORDAS, Thomas, Modos somáticos de atención, en Citro (comp.), Cuerpos Plurales. Antropología de y desde los cuerpos, Buenos Aires, Editorial Biblos. 2010

FOUCAULT, Michel (1987) Vigilar y castigar. Nacimiento de la prisión. México: Siglo XXI Editores.

GRIMSON, A., Culture and Identity: two different notions, in: Social Identities, vol. 16, nº 1, January, pp. 63-79. 2010

ROMAÑACH, J. y LOBATO, M. Diversidad funcional, nuevo término para la lucha por la dignidad en la diversidad del ser humano, Foro de vida independiente. 2005

ROMAÑACH, J. y PALACIOS, A.. El modelo de la diversidad: una nueva visión de la bioética desde la perspectiva de las personas con diversidad funcional (discapacidad), Intersticios: Revista Sociológica de Pensamiento crítico 2. (http://www.intersticios.es). 2008

WACOUANT, Loic. Entre las cuerdas: cuadernos de un aprendiz de boxeador. Buenos Aires: Siglo XXI Editores Argentina. 2006

WALSH, Catherine. Interculturalidad crítica, pedagogía decolonial. En: Villa W. y Grueso A. (comp.). Diversidad, interculturalidad y construcción de ciudad. Bogotá. 2008 


\section{NOTAS}

Encuentro con Sharon Fridman. 24 de mayo de 2020: Podes verlo en https://www.youtube.com/watch?v=hHxchS2MoGs.

ii Convocatoria del Encuentro: https://mica.org.ar/iii-encuentro-de-danza-e-inclusion/

iii Puede verse la agenda en https://mica.org.ar/?page_id=92

iv A partir de una conversación con el equipo de relevamiento y escritura del Evento Ciudad Moviente, elijo utilizar la modalidad os/as en vez de el lenguaje inclusivo pues los programas de lectura aun no lo reconocen y entonces las personas con disminución visual u otras que lo necesitaran, no podrían acceder a una correcta escucha-comprensión de este texto

"A lo largo de mis investigaciones he acuñado el concepto de "trayectoria corporal" para poder abordar el análisis de estos espacios de interaccion entre producción gestual y subjetividad Con este concepto pretendo trascender una descripción en términos estáticos y estructurales en pos de rescatar el carácter procesual y dinámico de las incorporaciones. Destaco su potencial para identificar y precisar modificaciones en el marco de las trayectorias individuales, pero sobre todo para ponderarlas a la luz de tendencias colectivas y/o espacios culturales más amplios.

vi Soy performer butoh desde hace 20 años, bioenergetista y antropóloga y docente. Para un mayor análisis de ello. Véase. Subjetividades en Movimiento. Reelaboraciones de la Danza Butoh en Argentina. Acceso libre y gratuito: http://publicaciones.filo.uba.ar/subjetividadesen-movimiento

vii Estos talleres estuvieron a cargo de L. Rossetto/M. Landa/F. Luna, Laisvie Andrea Ochoa Gaevska, David Señoran, Mariela Ruggeri, Cristina Turdo, Victoria Lagos, Rakhal Herrero, Inés Armas, Mariana Paz Marcolla, G. Torres/S. Iglesias, Compañías. ConCuerpos (Colombia), Ya Danza (Costa Rica), Sin Límites (Argentina), William Sánchez H (Colombia-Alemania), Mundana (Perú), Aparejo (Uruguay), Pulsiones (Argentina), AM (Venezuela),Andares (Argentina), Grupo Alma (Argentina), Sin Fronteras (Argentina), Proyecto PES (Brasil), Entre Colores y Sombras (El Salvador), Rommany Dear, (UK-Colombia). Para conocer mayores detalles de los talleres, compañías y profesores. Visite: https://mica.org.ar/?page_id=573

viii Consagrada el 13 de diciembre de 2006 por la Asamblea de las Naciones Unidas. Puede accederse desde el siguiente enlace: https://www.un.org/development/desa/disabilities-es/

${ }^{i x}$ La denominación de diversidad funcional surgió desde el propio colectivo y fue propuesto desde el derecho a decidir cómo el colectivo se auto-percibe y quiere ser nombrado. Romañach y Lobato (2005) refieren del siguiente modo: "las mujeres y hombres con diversidad funcional somos diferentes, desde el punto de vista médico o físico, de la mayor parte de la población. Al tener características diferentes, y dadas las condiciones de entorno generadas por la

Patricia Aschieri - Corporalidades diversas en movimiento. Descentrar la danza de la danza.

Revista Arte da Cena, v.6, n.2, ago-dez/2020.

Disponível em http://www.revistas.ufg.br/index.php/artce 
sociedad, nos vemos obligados a realizar las mismas tareas o funciones de una manera diferente, a veces a través de terceras personas [...] misma función, manera diversa" (p.3).

× En la encuesta realizada en el momento de inscripción con el interés de conocer si Ixs participantes necesitarían algún tipo de asistencia durante el evento se les realizaron algunas preguntas cuya respuesta era de carácter voluntario: Se les preguntó si poseían alguna dificultad corporal y también por su adscripción identitaria entre otras cuestiones. Del total de inscriptos/as ( $\mathrm{N}_{454}$ ) el $21 \%$ manifestó poseer algún tipo de dificultad. Y solo el 3, 7\% se autopercibió como discapacitado/a.

${ }^{x i} \mathrm{Al}$ reponer una historia de la Danza Integradora Gonzalez Gonz refiere que fue sus primeras acciones fueron a partir del "legado" que le dejó la Dra. Gertrude Krombholz de la Universidad de Munich, quien había dictado en 1990 en Buenos Aires el 1er Seminario Intensivo de Danza Integradora en silla de ruedas. Mas info en www.danzaintegradora.com.ar

xii Puede verse la entrevista completa en https://www.youtube.com/watch?v=cGA4 Nrcg5zU

xiii En Argentina la Ley $N^{\circ} 22.431$.

xiv En el campo de la discapacidad, "disca" es una marea habitual de referirse a su condición.

${ }^{x v}$ Agradezco especialmente a la coreógrafa y bailarina Mariana Ruggeri por sus observaciones al borrador de este texto, que permitió dar cuenta de un interesante juego dialógico de voces que incluí en esta versión final.. Ella es integrante del Movimiento Federal de Danza. Respecto de los derechos de los hacedores de la danza sostiene: "El Estado Argentino se ha declarado sostenida e históricamente indiferente para brindar desarrollo sustentable a los artistas de la danza, que cuando debieron quedarse en el país devinieron para siempre en artistas "emergentes", o eligieron otra profesión, por el simple instinto de supervivencia". Fuente: https://www.telam.com.ar/notas/201705/188366-ley-nacional-danza-argentina-marielaruggeri.html

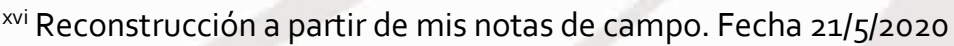

xvii Reconstrucción a partir de mis notas de campo. Fecha 21/5/2020

xviii Desde el Año 2008 se impulsan acciones en función de concretar políticas públicas para la danza en el territorio nacional. El Movimiento Federal de Danza,como continuación de lo iniciado desde el Movimiento por la Ley Nacional de Danza trabaja en la organización del sector desde las 8 regiones culturales del país con el objetivo de lograr legislaciones provinciales y la Ley Nacional de Danza . Para más info: www.movimientofederaldedanza.com.ar https://www.leynacionaldedanza.org/

xix Danza Sin Fronteras, que en una nota periodística fue caracterizada como la Mujer Maravilla

xx Publicada en la Revista Narraciones del Centro de Salud Mental N 1 (Julio 2020).

xxi Por ejemplo, en una entrevista, Walter Mignolo afirma desde la perspectiva decolonial, que en su grupo ya no se acepta ningún sustantitvo sin adjetivo, porque siempre conviene aclarar de dónde viene una idea o palabra antes de caer en darle un sentido único y universal. Acceso: https://www.lavaca.org/notas/a-desaprender-walter-mignolo-referente-del-pensamientodecolonial/

Patricia Aschieri - Corporalidades diversas en movimiento. Descentrar la danza de la danza. Revista Arte da Cena, v.6, n.2, ago-dez/2020.

Disponível em http://www.revistas.ufg.br/index.php/artce 
xxii Un interesante ejemplo es el de un importante dramaturgo argentino, Mauricio Kartun, quien dice que el mejor modo de explicar qué es lo que hace el teatro es decir que "el teatro teatra". El reomodo le da el protagonismo al verbo, que es totalizador e integrador, y genera un nuevo modo en el lenguaje.

*Patricia Aschieri, Artista Investigadora. Doctora en Antropología (UBA). Con formación en distintas técnicas y escuelas teatrales, especialmente en danza butoh. Coordinadora de Recursos Expresivos y Bionergetista. Coordina el Área de Investigaciones en Artes Liminales del Instituto de Artes del Espectáculo de la Facultad de Filosofía y Letras (UBA) y es profesora del departamento de Artes de la misma institución. Profesora de la Licenciatura en Psicomotricidad en la Universidad Nacional de Tres de Febrero (UNTREF). Integra el Área de Investigaciones en Ciencias del Arte - CCC Floreal Gorini. Dirige varios proyectos de investigación con especialización en las áreas de antropología de las corporalidades en movimiento y la performance y en perspectivas interculturales de prácticas socio-estéticas. También en enfoques teórico-metodológicos que incluyen la dimensión corporal de lxs investigadorxs como parte de los procesos de producción de conocimiento. Jurado de los Premios Teatro del Mundo (CCRRRojas-UBA), es integrante del grupo Descentradxs - Descentrar la Investigación en Danza y de la Red de Investigacón de y desde lod cuerpos.

Submissão: 19/10/2020

Aprovação: 14/12/2020

Patricia Aschieri - Corporalidades diversas en movimiento. Descentrar la danza de la danza.

Revista Arte da Cena, v.6, n.2, ago-dez/2020.

Disponível em http://www.revistas.ufg.br/index.php/artce 